\title{
Lexical Attrition of General and Special English Words after Years of Non-Exposure: The Case of Iranian Teachers
}

\author{
Reza Abbasian \\ Department of English, Faculty of Humanities, Islamic Azad University, Izeh Branch \\ Islamic Azad University, Izeh, Khoozestan, Iran \\ E-mail: Abbasian_reza@yahoo.com \\ Yaser Khajavi (corresponding Author) \\ Department of English, Faculty of Humanities, Islamic Azad University, Izeh Branch \\ Islamic Azad University, Izeh, Khoozestan, Iran \\ E-mail: yaserkhajavi@yahoo.com
}

\begin{abstract}
This study sought to investigate the rate of attrition in general and special vocabulary in and out of context. Participants of the study were 210 male Persian literature teachers with different years of non-exposure to English $(2,4,5,6,7,8$ \&10) after graduating from university. They were selected through purposive sampling from among 1000 Persian literature teachers from three provinces, namely Esfahan, Fars and Yasuj. Their age ranged between 25 and 35. The instrument included one translation task. The task consisted of 20 items of general words and 20 items of special words which were tested in and out of context.

Results indicated that the rate of attrition increased gradually as the years of non-exposure to English increased. Also, it was found that the rate of attrition in special and contextualized lexicon is respectively less than general and de-contextualized lexicon.
\end{abstract}

Keywords: Contextualization, Attrition, General words, Special words, De-contextualization

\section{Introduction}

"Language attrition" is the most common term used for any "Loss of language skills" that occurs after some years of non-exposure (Moorcraft \& Gardner, 1987, p.327). "Attrition refers to the non-pathological loss of a language in bilinguals; generally speaking, changes in the linguistic environment and termination of an instructional program may lead to attrition” (Kopke \& Schmid, 2004, cited in Marefat \& Rohshad, 2007, p. 86).

"Language attrition (language loss) is a multi-dimensional phenomenon which has been studied from a variety of perspectives e.g. psycholinguistics, neurolinguistics, and sociolinguistics" (Gurel, 2004, p.53).

The body of research includes studies in first language (L1) as well as second language (L2) attrition, including generally non-pathological cases.

L2 attrition may occur in students who learn a second language in school but do not use it once classes have been completed (de Bot \& Weltens, 1995, p.154). L2 attrition may occur in different aspects of language like grammar or vocabulary.

According to Schmid (2007, p.137 ) "the process of attrition can be seen as both an internally and externally induced phenomenon, determined by contact with L2, as well as the influence of L1 (cited in Bar-Shalom \& Zaretsky, 2008, p.282).

It has been argued that lexical knowledge is probably the most vulnerable aspect of the language systems to word loss (Weltens \& Marjon, 1993; Al-Hazemi, 2000). Yoshitiomi (1992) pointed out that vocabulary is more likely than grammar to be subject to attrition in advanced L2 learners who had acquired the language in a natural setting. She stated that lexical attrition may be as difficult to detect as grammatical attrition, and at the very beginning, attrition is more apparent in situations that need a variety of language skills than in situations that focus on testing one specific subskill, such as vocabulary or grammar. Morshedian $(2008$, p.89) maintains that "considering attrition of different elements of L2 lexicon including dichotomies such as specific vs. general words, abstract vs. concrete words we can find out about how each category is affected by attrition and then figure out teaching/learning tasks to prevent it". Present study is a response to such a call. This study aimed at answering the following questions. 


\section{Research Questions}

1) Is there any difference between attrition of special and general English words after years of non-exposure?

2) Is there any difference between attrition of contextualized and de-contextualized English words after years of non- exposure?

\section{Literature review}

\subsection{Attrition in contextualized vs. de-contextualized lexicon}

Different theories have been proposed regarding language attrition.

De Groot \& Keijzer (2000) maintain that "what is hard to learn is easy to forget" (p.1). When learning vocabulary, the words such as cognate and concrete words were kept in memory better than the other types of the words. Another related theory is the "best learned last forgotten" theory that believes in retention of integrated items in memory in comparison to isolated ones (Weltens, 1989, p.7). Similar concept exists in "inverse relation hypothesis," which suggests that the amount of subsequent attrition decreases as the level of proficiency increases (Yoshitomi, 1992, p. 296, Hansen \& Reetz-Kurashige, 1999). As Yoshitomi (1992) stated, this hypothesis is confirmed by Bahrick's research (1984). In an attrition study, Bahrick found that those with low proficiency in Spanish language made no difference with those who had not ever learned Spanish. He also found that those with high proficiency performed better in that study.

De Groot \& Keijzer (2000) also suggested that the higher the imageability of the words, the easier to be learned and thus less attired. Since the imageability and concreteness were positively correlated, they believed that concrete words were less attired than abstract ones. Ellis and Beaton (1993) achieved the same result, but they believed in independency of imageability with concreteness of attrition.

They also found a strong correlation between imageability and context availability of some words as they mentioned "how easy it is to think of a context"(p.35). They believed that concreteness and context availability "anchor the new FL words in memory" (p.38), so they are better retained and recalled.

De Groot \& Keijzer (2000) stated that words that were more difficult to learn were easily forgotten. They also found that words that were both concrete and cognate and therefore easier to learn, retain in memory more than non-cognate and abstract ones (p.16).

Neisser (1984) stated "isolated" and less connected information to schema will be forgotten; however, associated data to schema are less attired and only "relatively redundant and systematic knowledge will retain better in one's memory (p.34). Another complementary hypothesis is the "best learned last forgotten" hypothesis which mentions that the best learned material are those that are more complete and better connected than the others.

Unlike Neisser's hypothesis, Yoshitomi (1999) considered the connected information as a whole and believed that since one missing part of the information influences the whole parts, well connected information is more prone to attrition than the other kinds (p.93).

\subsection{Attrition in general and special words}

Some researches went through the components of language, such as vocabulary or grammar and believed that they are more vulnerable to attrition; others particularly concentrated on the subcomponents of language. For example, Weltens (1989) and de Bot \& Weltens (1991) proposed that some commonly speech acts are resistant to attrition such as greeting, congratulation and "closed set" words (p.9) due to overlearning.

This pattern, however, may not always be true of L2/FL learners (Berko-Gleason, 1982, cited in de Bot \& Weltens, 1991). Overlearning, and thus better retention, of this type of pragmatic information is more likely when the language is thoroughly learned in a naturalistic situation (Berman \& Olshtain, 1983, cited in de Bot \& Weltens, 1991, and Weltens, 1989).

In the case of general and special words, Olshtain \& Barzilay (1991) found out that specific nouns are more prone to attrition than general ones in that the participants in this research switched to general semantic features and avoided to use the specific nouns.

On the contrary to some researchers who focused on elements of language, such as vocabulary or grammar, other researchers have focused specifically on which elements of lexicon are most likely to be lost. This is argued in those studies that the inability of some EFL learners to recognize some words was due to the fact that certain words might have been forgotten. Many words were also hard to recognize even when clues were given. The phenomenon of word loss, however, was not investigated with adult Iranian learners of English to support the above argument. A line of research has been done on attrition of components and sub-components of language. 
Al-Hazemi (2000) investigated attrition of general and special vocabulary knowledge of some Saudi military officers. The duration of language disuse was 12 years after graduating from King Abdul Aziz military Academy. The results of this study showed that the ability of participants to recall both general and special vocabulary was too low (less than $45 \%$ recall). The results also revealed that the period of English disuse had no effect on recall of lexical knowledge.

In another study, Marefat \& Rohshad (2007) examined L2 attrition of vocabulary in adult Iranian learners with different proficiency levels. They used a 40 item vocabulary test to measure productive and receptive vocabulary knowledge of participants. The results showed no significant difference between attrition of concrete and abstract nouns taking proficiency level of participants into account. Also, participants who had three months of disuse of English showed significant amount of attrition in non contextualized nouns.

Jahangard (2007) examined retention of technical and general vocabulary among 33 Iranian male language learners. They were high school students majoring in Physics and Mathematics field. Two word lists were used for assessing general and special word knowledge of the students. The results showed no significant difference between retention of general and technical vocabulary in the study.

In the most recent study, Morshedian (2008) investigated lexical attrition/retention of productive versus receptive word knowledge of Iranian EFL learners considering their level of proficiency. The duration of English disuse was three months. The results of this study revealed that productive knowledge is less resistant to attrition than receptive knowledge.

\section{Method}

\subsection{Setting and Participants}

The study was conducted in three neighboring provinces of Iran i.e. Esfahan, Fars, and Yasuj. They are located in the southwest and center of Iran. The rationale for selection of these provinces was that they were available to the researchers and also they had much in common in terms of sociolinguistic and geographical factors. Therefore, we were able to handle intervening variables like sociolinguistics factors and come to much more precise results.

Participants of the study were 210 male Persian literature teachers with different years of experience and different English background. They were selected through purposive sampling from among 1000 Persian literature teachers from abovementioned provinces. Their age ranged between 25 and 35 .

One reason why Persian literature teachers were selected as the participants is the fact that Persian literature teachers have the least contact with English language after graduating from university.

Another reason for this selection was the fact that the population of Persian literature teachers was more than other teachers of other courses according to statistics of Ministry of Education; likewise, they had passed general English course in university or teacher training center. So, it was possible to investigate the lexical attrition (both general and special).

For the sake of homogeneity, the participants were divided into seven groups of thirty with different years of non-exposure i.e. 2, 4, 5, 6, 7, 8, and 10 and only those who had scored between 15-17 in the English course were selected. This information was gathered using a questionnaire.

\subsection{Instrument}

The instrument included one translation task from English to Persian. The task consisted of 20 items of general words and 20 items of special words which were chosen based on the most frequently use reentries in General English Book of Human Sciences taught at most Iranian universities for more than 11 years.

The task was divided into two sections. In the first section, the lexical items were presented in isolation. In the second section, they were presented in context such that every lexical item both general and special appeared twice in the task. However, the isolated items were presented before the contextualized section so that there would be no effect of context on the performance of participants.

We conducted both general and special tests with a time interval of one week since the same 20 words used in and out of context. Broadly speaking, a subject should have answered to two sets of 20 lexicon, special and general, both in context and out of context and translate them from English to Persian.

\subsection{Procedure}

At first 1000 Persian Literature teachers were selected randomly from three provinces of Esfahan, Fars and Yasuj. 
To homogenize the participants, they were given questionnaires in order to classify them based on years of non-exposure to English and the scores they had achieved from General English Book (15-17).

They were divided into 7 groups of thirty respectively, with 2, 4, 5, 6, 7, 8 and 10 years of non- exposure to English, so they were 210 subjects.

In the first session, the participants were presented 20 special English words and 20 general English words in isolation and they were required to translate the words into Persian. After a week, the same words used in context were presented to them to be translated into Persian.

The arrangement of exams was observed so that there would be no effect of context on the performance of participants. Meanwhile, the time allocated to each exam was 10 minutes, it means 30 seconds for a word. The score allocated for each word was 5, so the top score for each exam was 100. Finally, each subject was tested by four kinds of test and the data was collected.

\section{Results}

This study sought to investigate the rate of attrition in general and special vocabulary in and out of context. In order to investigate the research questions a number of statistics were run. The results are presented in this section.

$R Q 1$. Is there any difference between attrition of special and general English words after years of non-exposure?

Tables 1 and 2 show the descriptive statistics for participants' scores on general and special tests both in and out of context based on years of non exposure to English.

\section{Insert Tables $1 \& 2$ Here}

The total mean scores of participants in general and special word tests out of context show that participants' scores in special test $(\mathrm{M}=35.0476, \mathrm{SD}=19.2502)$ is more than general one $(\mathrm{M}=27.3095, \mathrm{SD}=18.7472)$; likewise in context, the total mean scores of items in special and general test are respectively $(\mathrm{M}=47.0476, \mathrm{SD}=21.5399)$ and $(\mathrm{M}=36.1667, \mathrm{SD}=21.3132)$.

A repeated measures ANOVA was conducted to investigate any significant difference between attrition of special and general lexicon after years of non-exposure. As table 3 shows, there is a significant difference between attrition of special and general lexicon within each group after different years of non-exposure ( $\mathrm{F}=598.644$, $\mathrm{p}=0.000$ ). It means that the degree of attrition in general words is more than special ones.

\section{Insert Table 3 Here}

$R Q 2$. Is there any significant difference between attrition of contextualized and de-contextualized English words after years of non- exposure?

The mean scores of participants in contextualized and de-contextualized word tests show that participants' scores in contextualized test are more than de-contextualized one.

Another repeated measures ANOVA was conducted to investigate any significant difference between attrition of contextualized and de-contextualized lexicon after years of non-exposure. As table 4 shows, there is a significant difference between attrition of contextualized and de-contextualized lexicon within each group after different years of non-exposure $(\mathrm{F}=989.148, \mathrm{p}=0.000)$. It means that the degree of attrition in de-contextualized lexicon is more than contextualized ones.

\section{Insert Table 4 Here}

\section{Discussion and Conclusion}

Based on the results, it is concluded that there is a rule governed relationship between the rise of lexical attrition and the increase of years of non-exposure to English; it means that there is a gradual rise of lexical attrition and gradual increase in years of non-exposure to English. Additionally, it can be said that non-exposure to English is of the most prominent causes of lexical attrition.

The data also demonstrates that special words are more resistant to attrition than general words. These results are in contrast with findings of Olshtain \& Brazily (1991) who maintain that specific nouns are more prone to attrition than general words. Also these results are in conflict with findings from Jahangard (2007) who maintains that the pace of forgetting for general and special vocabulary is the same.

Considering the second research question regarding the difference between attrition of contextualized and de-contextualized lexicon, it was found that the rate of attrition in contextualized lexicon is less than de-contextualized one. These results are in line with findings from Neisser (1984) who maintains that isolated 
and not connected knowledge to schemata will be forgotten earlier than well connected knowledge to schemata. One possible explanation for participants' superior performance in contextualized lexicon test may be that context helps testees guess the meaning of not known words. The results are not in agreement with Yoshitomi (1999) who believes that "an isolated portion of knowledge may be more resistant to loss "(p.93). The rationale behind Yoshitomi's idea is that being well-connected may cause difficulty in retention of one part due to problem in another part of the system.

These findings have several pedagogical implications. They imply that there should be an English course during the course of time for teachers since non-exposure to English endangers lexical knowledge of them. In service learning classes, the teachers should also be classified based on years of non-exposure to English in order to have high rate of efficiency in those classes. Furthermore, it is better to put emphasis on general words than special words during English courses. In addition, when teachers want to teach vocabulary, it is wise to teach general and special vocabulary in context and ask students to practice them in context. As general vocabulary is more vulnerable to attrition, teachers should put more emphasis on this type of vocabulary so as to make these words resistant to attrition.

Attrition has a broad area to be studied. As such, there are some other aspects which can be investigated. Present research was conducted on lexical attrition and studied some Iranian adult EFL Learners; it would be promising to consider some teachers from other nationalities to study their performance. To make the research more specific and precise, one may narrow down the scope and choose mono-syllabic lexical attrition in comparison to di-syllabic, three-syllabic or poly-syllabic lexical attrition. Someone may narrow down the lexicon and compare the degree of attrition between nouns and verbs or nouns and adjectives. It is also possible to go further and compare the rate of grammatical attrition with lexical attrition.

Furthermore, it would be promising to investigate if the results change in case the participants are mixed (i.e. males and females) or if they are only females. Also, further research may investigate if the results change in case the interval between the tests (respectively words "out of context" and "in context") is longer than a week.

It should be noted that due to limitations, the study was conducted only in three provinces of the country, there fore generalizing the findings to other situations should be done with caution.

\section{Acknowledgement}

The authors are grateful to Cindy $\mathrm{Xu}$ and two anonymous reviewers for their insightful comments on earlier version of this paper.

\section{References}

Al-Hazemi, H. (2000). Lexical attrition of some Arab speakers of English as a foreign

Language: a study of word loss. The Internet TESL Journal 1, (12). Retrieved May, 17, 2009 from http://iteslj.org/Articles/Al-Hazemi-Attrition.

Bahrick, H.P. (1984). Semantic memory content in premature: Fifty years of memory for Spanish learned in school. Journal of Experimental Psychology, 113, 1-29.

Bar-Shalom, E. \& Zaretsky, E. (2008). Selective attrition in Russian-English bilingual children: Preservation of grammatical aspect. International Journal of Bilingualism, 12, 281-302.

Berko-Gleason, J. (1982). Insights from child language acquisition for second language loss. In R. D. Lambert \& B. F. Freed (Eds.). The loss of language skills (pp. 13 -23). Rowley, London, Tokyo: Newbury House

de Bot, K. \& Weltens, B. (1991). Recapitulation, regression, and Language loss. In H.W. Seliger \& R.M. Vago (Eds.), First language Attrition . (pp. 31-52). Cambridge: Cambridge University Press.

de Bot, K. \& Weltens, B. (1995). Foreign language attrition. Annual Review of Applied Linguistics, 15, 151-164.

de Groot, A. \& Keijzer R. (2000). What hard to learn is easy to forget: The roles of word concreteness, cognate status, and word frequency in foreign language learning and forgetting. Language Learning, 50, 1-56.

Ellis, N. \& Beaton A. (1993). Psycholinguistic determinants of foreign language vocabulary learning. Language learning, 43, 559-617.

Gurel A. (2004). Selectivity in L2-induced L1 attrition: A psycholinguistic account. Journal of Neurolinguistics.17, 53-78.

Hansen, L.\& Reetz-Kurashige, A. (1999). Investigating second language attrition: An introduction. In L. Hansen (Ed.), Second Language attrition in Japanese Contexts (pp. 3-20). Oxford: Oxford University press 
Jahangard, A. (2007). Which Word Types (Technical or General) are more difficult to Retain by the Iranian High School Learners? The Asian ESP Journal, 3, 6-23.

Kopke, B. \& Schmid, M. (2004). Language attrition: The next phase. B. Kopke, M.S. Schmid, M. Keijzer \& S. Dostert (Eds.), First language attrition: Interdisciplinary perspectives on methodological issues (pp. 1-47). Amsterdam: John Benjamins.

Marefat, H \& Rohshad, A. (2007). Second language attrition: Are different nouns equally likely to be lost? Porta Linguarum, 8, 85-98.

Moorcraft, R. \& Gardner, R.C. (1987). Linguistic factors in second language loss. Language Learning, 37(3), 327-340.MRC Psycholinguistic Database. Available online at: http://wwww.psy.uwa.edu.au/mrcdatabase/uwa_mrc.htm.

Morshedian, M. (2008). The Role of Initial English as Foreign Language Proficiency in Lexical Attrition/Retention of Iranian Learners: Is Productive or the Receptive Word Knowledge of Learned Nouns More Likely to Be Lost?. Linguistics Journal. 3, 75-99.

Neisser, U. (1984). Interpreting Harry Bahrick's discovery: What confers immunity against forgetting? Journal of Experimental Psychology, 113, 25-32.

Olshtain, E. \& Barzilay, M. (1991). Lexical retrieval difficulties in adult language attrition. In H.W. Seliger \& R.M. Vago (Eds.), First Language Attrition. (pp. 139-150). Cambridge University Press.

Schmid, M. S. (2007). The role of L1 use for L1 attrition. In B. Kopke, M.S. Schmid, M. Keijzer \& S. Dostert (Eds.), Language attrition: Theoretical perspectives. (pp. 135-154). Amsterdam: John Benjamins.

Weltens, B., \& Marjon G. (1993). Attrition of vocabulary knowledge. In: R. Schreuder \& B. Weltens (Eds.) The bilingual lexicon. Amsterdam: Benjamins.

Weltens, B. (1989). The attrition of French as a foreign language. Dordrecht: Foris Publications.

Yoshitomi, A. (1992). Towards a model of language attrition: Neurobiological and psychological contributions. Issues in Applied Linguistics, 3, 293-318.

Yoshitomi, A. (1999). On the loss of English as a second language by Japanese returnee children. In L. Hansen (Ed.). Second language attrition in Japanese contexts (pp. 80-111). New York: Oxford University Press.

Table1. participants' scores on general tests in and out of context based on years of non exposure to English

\begin{tabular}{|c|c|c|c|c|c|c|}
\hline $\begin{array}{l}\text { General words } \\
\text { Out of context }\end{array}$ & & & $\begin{array}{l}\text { General words } \\
\text { In context }\end{array}$ & & & \\
\hline $\begin{array}{l}\text { years of } \\
\text { non-exposure }\end{array}$ & Mean & Std. Deviation & $\begin{array}{l}\text { years of } \\
\text { non-exposure }\end{array}$ & Mean & Std. Deviation & $\mathrm{N}$ \\
\hline 2.00 & 57.1667 & 10.9610 & 2.00 & 68.6667 & 11.2137 & 30 \\
\hline 4.00 & 41.0000 & 9.2289 & 4.00 & 50.8333 & 10.4290 & 30 \\
\hline 5.00 & 35.6667 & 8.9763 & 5.00 & 49.1667 & 10.4290 & 30 \\
\hline 6.00 & 22.6667 & 8.1720 & 6.00 & 30.3333 & 9.0909 & 30 \\
\hline 7.00 & 17.5000 & 7.5144 & 7.00 & 24.6667 & 9.4626 & 30 \\
\hline 8.00 & 10.6667 & 6.6609 & 8.00 & 17.6667 & 8.0658 & 30 \\
\hline 10.00 & 6.5000 & 5.8942 & 10.00 & 11.8333 & 8.0391 & 30 \\
\hline Total & 27.3095 & 18.7472 & Total & 36.1667 & 11.2137 & 210 \\
\hline
\end{tabular}


Table 2. participants' scores on special tests in and out of context based on years of non exposure to English

\begin{tabular}{|c|c|c|c|c|c|c|}
\hline \multicolumn{3}{|l|}{$\begin{array}{l}\text { Special words } \\
\text { Out of context }\end{array}$} & \multicolumn{4}{|l|}{$\begin{array}{l}\text { Special words } \\
\text { In context }\end{array}$} \\
\hline years of & Mean & Std. Deviation & years of & Mean & Std. Deviation & $\mathrm{N}$ \\
\hline non-exposure & & & non-exposure & & & \\
\hline 2.00 & 63.8333 & 10.0587 & 2.00 & 74.0000 & 8.7494 & 30 \\
\hline 4.00 & 49.6667 & 8.6037 & 4.00 & 67.1667 & 7.9528 & 30 \\
\hline 5.00 & 44.5000 & 8.5450 & 5.00 & 60.3333 & 9.0909 & 30 \\
\hline 6.00 & 32.8333 & 8.9715 & 6.00 & 45.6667 & 10.8066 & 30 \\
\hline 7.00 & 25.3333 & 9.8202 & 7.00 & 38.0000 & 10.3890 & 30 \\
\hline 8.00 & 16.6667 & 7.4664 & 8.00 & 25.6667 & 8.1720 & 30 \\
\hline 10.00 & 12.5000 & 6.3991 & 10.00 & 18.5000 & 8.6253 & 30 \\
\hline Total & 35.0476 & 19.2502 & Total & 47.0476 & $\mathrm{SD}=21.5399$ & 210 \\
\hline
\end{tabular}

Table 3. The results of repeated measures ANOVA regarding the difference between attrition of general and special words

\begin{tabular}{llllll}
\hline Source & FACTOR2 & Type III Sum of Squares & df & Mean Square & F \\
\hline FACTOR2 & Linear & 7229.301 & 1 & 7229.301 & 598.664 \\
\hline Error(FACTOR2) & Linear & 2523.824 & 209 & 12.076 & .000 \\
\hline
\end{tabular}

Table 4. The results of repeated measures ANOVA regarding the difference between attrition of contextualized and de-contextualized words

\begin{tabular}{lllllll}
\hline Source & FACTOR2 & Type III Sum of Squares & df & Mean Square & F & Sig. \\
\hline FACTOR2 & Linear & 3795.015 & 1 & 3795.015 & 989.148 & .000 \\
\hline Error(FACTOR2) & Linear & 801.860 & 209 & 3.837 & & \\
\hline
\end{tabular}

General Terms

\begin{tabular}{|l|l|}
\hline 1.The public & 11.audience \\
\hline 2.Particular & 12.chief \\
\hline 3.contemporary & 13.creatures \\
\hline 4.civilized & 14.surprising \\
\hline 5.combination & 15.principle \\
\hline 6.invention & 16.evidencce \\
\hline 7.sculpture & 17.trace \\
\hline 8.verse & 18.bowl \\
\hline 9.prose & 19.clay \\
\hline 10.wide & 20.pottery \\
\hline
\end{tabular}

Special Terms

\begin{tabular}{|l|l|}
\hline 1.rhyme & 11.paradox \\
\hline 2.hemistich & 12.rhetoric \\
\hline 3.couplet & 13.symbolism \\
\hline 4.metaphor & 14.literary \\
\hline 5.simile & 15.critic \\
\hline 6.epic & 16.colloquial \\
\hline 7.lyric & 17.interpretation \\
\hline 8.comedy & 18.quatrains \\
\hline 9.tragedy & 19.song poem \\
\hline 10.contrast & 20.syllabicpoem \\
\hline
\end{tabular}

